\title{
Características morfogênicas e estruturais do capim-Xaraés submetido a intensidades de desfolhas ${ }^{1}$
}

\author{
Morphogenesis and structural characteristics of grass Xaraés under different intensities \\ of court
}

\author{
RODRIGUES, Rosane Cláudia ${ }^{2 *}$; AMORIM, Susan Emanuelly Pinheiro ${ }^{3}$; MELLO, \\ Maria Antônia de Araújo ${ }^{2}$; SANTOS, Clésio Costa ${ }^{2}$; SANCHÊS, Sâmara Stainy \\ Cardoso $^{2}$; GALVÃO, Carlos Magno Lima
}

\author{
${ }^{1}$ Pesquisa financiada pela Fundação de Amparo à Pesquisa e ao Desenvolvimento Científico e \\ Tecnológico do Maranhão. \\ ${ }^{2}$ Universidade Federal do Maranhão, Centro de Ciências Agrárias e Ambientais, Departamento de \\ Zootecnia, Chapadinha, Maranhão, Brasil. \\ ${ }^{3}$ Universidade Federal do Piauí, Centro de Ciências Agrárias, Teresina, Piauí, Brasil. \\ *Endereço para correspondência: rosanerodrig@gmail.com
}

\section{RESUMO}

Objetivou-se avaliar as características morfogênicas e estruturais do capim-Xaraés submetido a cinco alturas de cortes $(10 ; 20 ; 30$; 40 e $50 \mathrm{~cm})$ com intervalo de corte baseado na interceptação luminosa (IL) pelo dossel durante a rebrotação (95\% de IL). Utilizou-se o delineamento inteiramente casualizado, num fatorial $5 \times 2$, com cinco repetições. As avaliações foram realizadas de março a novembro de 2011, nas variáveis: taxa de aparecimento foliar (TApF), taxa de alongamento foliar (TALF), taxa de alongamento do colmo (TALC), comprimento final da folha (CF), taxa de senescência foliar (TSF), duração de vida das folhas (DVF), número de folhas vivas por perfilho (NFV) e número vivo de perfilhos (NVP). Observou-se que as alturas de cortes de 30 a $50 \mathrm{~cm}$, resultaram em maior TALC, TALF, TApF, TSF, DVF, NFV e CF. As características TALC, TALF, TApF, TSF, NFV e CF apresentou valores mais elevados durante $\mathrm{o}$ período chuvoso. Enquanto, o filocrono e, a DVF em $40 \mathrm{~cm}$ apresentou valores mais elevados no período da seca. O NVP não foi afetado pelas alturas de cortes ou época do ano. A altura de corte do capim-Xaraés recomendada para essas condições edafoclimáticas situa-se entre 30 e $50 \mathrm{~cm}$.

Palavras-chave: altura de corte, dossel, interceptação luminosa, morfogênese

\section{SUMMARY}

Aimed to evaluate the morphogenetic and structural characteristics of grass Xaraés subjected to five heights of sections $(10,20,30$, 40 and $50 \mathrm{~cm}$ ) with cutting interval based on (LI) by the canopy during regrowth (95\% IL). We used a completely randomized design in a factorial $2 \times 5$ with five replications. The evaluations were conducted from March to November 2011, the following variables: leaf appearance rate (LAR), leaf elongation rate (LER), stem elongation rate (SER), final leaf length (LL), senescence rate leaf (SRL), life span of leaves (LSL), number of green leaves per tiller (NLL) and live tiller number (LNT). It was observed that the heights of cuts by 30 to $50 \mathrm{~cm}$ resulted in higher SER, LER, LAR, SRL, LLS, NLL and LL. The SER, LER, LAR, SRL, NLT and LL characteristics showed higher values during the rainy season. While the phyllochron and LLS at $40 \mathrm{~cm}$ showed higher values in the dry season. The LNT was not affected by the heights of cuts or time of year. The cutting height of the grass Xaraés recommended for these environmental conditions is between 30 and $50 \mathrm{~cm}$.

Keywords: canopy, cutting height, light interception, morphogenesis 


\section{INTRODUÇÃO}

A morfogênese é definida como a dinâmica de geração e expansão da forma da planta no espaço, podendo ser expressa em termos de aparecimento (organogênese) e expansão de novos órgãos e de sua senescência (LEMAIRE, 1997). O conhecimento da morfogênese torna-se uma ferramenta poderosa para auxiliar na definição de estratégias de manejo da pastagem, pois em função de ser baseada no acompanhamento da dinâmica do crescimento e desenvolvimento das lâminas foliares e do colmo dos perfilhos, produz uma espécie de raio- $X$ do que esta acontecendo com a planta forrageira, e aliada com algumas características estruturais do dossel forrageiro, pode-se determinar a dinâmica do acúmulo de forragem da pastagem (ALEXANDRINO et al., 2004).

Apesar de serem determinadas pelo genótipo da planta forrageira, vários trabalhos apontam que, as diversas características que definem a morfogênese, sofrem interferência de vários fatores, como: época do ano (PACIULO et al., 2003), nutrição mineral (ALEXANDRINO et al., 2004) e radiação (DIAS FILHO, 2000).

Por outro lado, alguns fatores como a frequência de desfolhação (determinadas por intervalo de tempo entre ciclos de pastejo), e a intensidade do pastejo imposto causam grande estresse para a planta, cuja magnitude depende da severidade da desfolhação (GOMIDE et al., 2002). É fundamental a utilização de intervalos de pastejo que respeitem e possibilitem a recuperação das plantas. Sousa et al. (2011), avaliaram as características morfogênicas e estruturais do capim-Xaraés submetido a três alturas de corte $(15 ; 20$ e $25 \mathrm{~cm})$ quando atingidos $95 \%$ de interceptação de luz durante a rebrotação e, verificaram que a variação na severidade de corte pouco influenciou as características morfogênicas e estruturais dessa gramínea.

A intensidade de desfolha, bem como a freqüência com que esse evento ocorre é fundamental para o manejo eficiente tanto da pastagem no sentido de assegurar a rebrota subseqüente como do pastejo no sentido de controlar e/ou favorecer a estrutura do dossel que, por sua vez irão interferir no acúmulo de forragem. Dessa maneira, o entendimento de como essa modificação ocorre e como ela se direciona possibilita a base necessária para que o manejo do pastejo otimize a produção animal, sem afetar a sobrevivência e perenidade da comunidade vegetal. Assim, objetivou-se com o presente estudo avaliar as características morfogênicas e estruturais do capim-Xaraés submetido a diferentes intensidades de desfolhas e épocas do ano.

\section{MATERIAL E MÉTODOS}

O experimento foi conduzido no Setor de Forragicultura do Centro de Ciências Agrárias e Ambientais da Universidade Federal do Maranhão, em Chapadinha, região do Baixo Parnaíba, situada à latitude $03^{\circ} 44^{\prime} 33^{\prime \prime}$ 'S, longitude $43^{\circ} 21 ' 21^{\prime \prime} \mathrm{W}$, no período de janeiro a novembro de 2011. O clima é tropical úmido, a temperatura média do período chuvoso foi de $26,25^{\circ} \mathrm{C}$ e de $27,77^{\circ} \mathrm{C}$ no período seco. A precipitação ocorrida no período experimental encontra-se na Figura 1. 


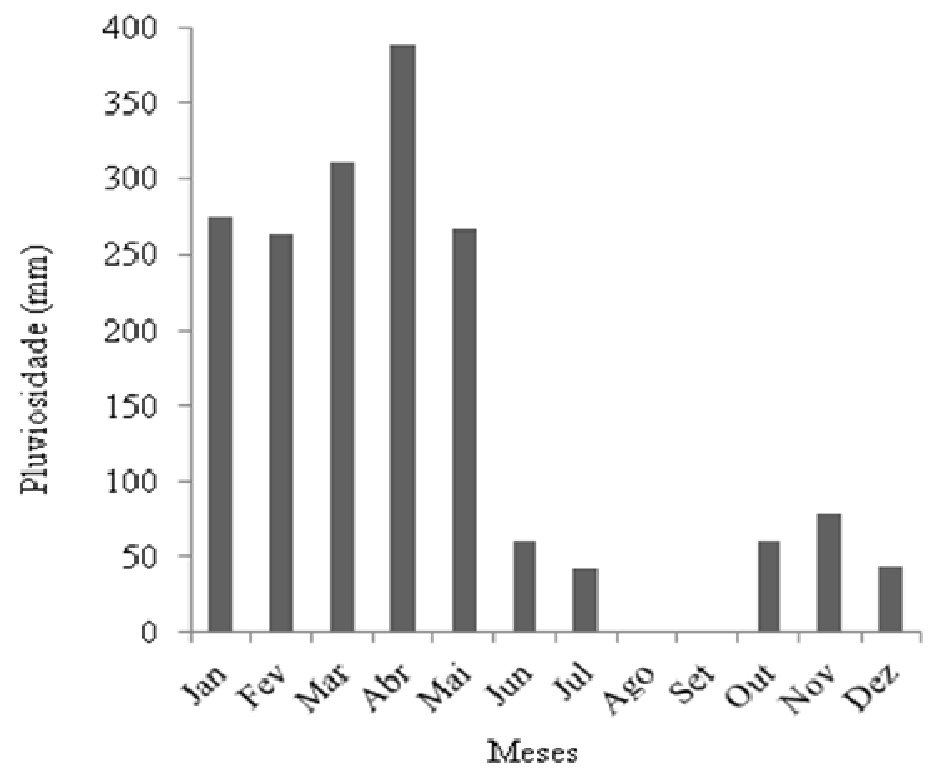

Figura 1. Precipitação pluviométrica no município de Chapadinha - MA, de janeiro a dezembro de 2011

O solo do local do experimento foi classificado como Latossolo Amarelo (EMBRAPA, 1999) apresentando as seguintes características químicas: $\mathrm{pH}$ em $\mathrm{CaCl}_{2}=4,8 ; \mathrm{M} . \mathrm{O} .=17 \mathrm{~g} / \mathrm{dm}^{3} ; \mathrm{P}=7 \mathrm{e}$ $\mathrm{S}=8 \mathrm{mg} / \mathrm{dm}^{3}$, respectivamente; $\mathrm{K}=2,5$, $\mathrm{Ca}=4, \mathrm{Mg}=2, \mathrm{H}+\mathrm{Al}=21, \mathrm{Al}=1, \mathrm{CTC}=$ $29, \mathrm{SB}=8 \mathrm{mmol}_{\mathrm{c}} / \mathrm{dm}^{3}$, respectivamente; $\mathrm{V}=29 \%$ e $\mathrm{m}=10 \%$; e $\mathrm{B}=1,31, \mathrm{Cu}=0,1$, $\mathrm{Fe}=31, \mathrm{Mn}=0,3$ e $\mathrm{Zn}=0,4 \mathrm{mg} / \mathrm{dm}^{3} . \quad \mathrm{O}$ preparo do solo e as práticas corretivas foram realizados entre outubro e novembro de 2010 e o plantio realizado em janeiro de 2011. Utilizou-se o equivalente a $70 \mathrm{~kg}$ de $\mathrm{P}_{2} \mathrm{O}_{5} / \mathrm{ha}$ e $60 \mathrm{~kg} / \mathrm{ha}$ de $\mathrm{K}_{2} \mathrm{O}$, na forma de supersimples e cloreto de potássio, respectivamente. A fonte de fósforo foi aplicada de uma só vez, na implantação do experimento e o potássio foi parcelado em três vezes $(20 \mathrm{~kg}$ de $\mathrm{K}_{2} \mathrm{O} /$ ha) e aplicado juntamente com o nitrogênio. Ao longo do período chuvoso, foi realizada a adubação de manutenção, com $150 \mathrm{~kg} /$ ha de $\mathrm{N}$, na forma de uréia, divididos em três aplicações de $50 \mathrm{~kg} / \mathrm{ha}$.
As avaliações foram iniciadas no dia 07/03/2011. Para tanto, foi realizado um corte de nivelamento, onde em cada parcela, o capim foi rebaixado na sua respectiva altura.

$\mathrm{O}$ delineamento experimental utilizado foi $o$ inteiramente casualizado com arranjo em parcelas subdividas sendo os períodos (chuvoso e seco), as parcelas e as subparcelas, as alturas de cortes $(10$; $20 ; 30 ; 40$ e $50 \mathrm{~cm}$ ), com cinco repetições totalizando 25 unidades experimentais. $\mathrm{O}$ intervalo de corte foi baseado na interceptação luminosa (IL) pelo dossel durante a rebrotação $(95 \%$ de IL) utilizando-se o aparelho analisador de dossel AccuPAR Linear PAR/LAI ceptometer, Modelo PAR-80 (DECAGON\% Devices).

As avaliações das características morfogênicas e estruturais foram realizadas em 10 perfilhos vegetativos, marcados com fios coloridos. $\mathrm{O}$ acompanhamento do desenvolvimento dos perfilhos ocorreu em intervalo de três dias no período chuvoso e, a cada sete dias no período seco do ano, 
realizado com o auxílio de régua milimetrada. A partir dos dados obtidos pela análise de crescimento das estruturas das plantas, foram calculadas as seguintes variáveis: taxa de alongamento do colmo (TALC): diferença obtida entre os comprimentos finais e iniciais dos colmos, dividida pelo número de dias decorridos no período de avaliação; número de folhas vivas por perfilho (NFV): número de folhas vivas presente no perfilho no final de cada período de avaliação; número vivo de perfilhos (NVP): número de perfilhos vivos presente na planta avaliada no final de cada período de avaliação; comprimento final da lâmina foliar $(\mathrm{CF})$ : comprimento do ápice até a lígula da folha totalmente expandida de cada folha do perfilho; taxa de alongamento da lâmina foliar (TALF): diferença obtida entre os comprimentos finais e inicias das lâminas foliares, dividida pelo número de dias decorridos no período avaliação; duração de vida das folhas (DVF): tempo em que a folha permaneceu viva após a completa exposição da lígula; taxa de aparecimento foliar (TApF): obtida pelo número de folhas surgidas nos perfilhos marcados de cada parcela, dividido pelo número de dias decorridos no período avaliação; taxa de senescência foliar (TSF): área da lâmina foliar senescente nos perfilhos marcados, obtido pelo acúmulo de material morto $(\mathrm{em} \mathrm{cm})$, através da divisão do valor encontrado pela quantidade de dias decorridos no período avaliação. $\mathrm{O}$ filocrono foi calculado como o inverso da TApF (1TApF).

Os dados coletados foram tabelados de acordo com os tratamentos e submetidos a testes que assegurasse as prerrogativas básicas para que os dados pudessem ser submetidos a análise de variância. Primeiramente, foi realizada uma analise utilizando o teste " $F$ ", no caso de efeitos significativos chegou-se a conclusão de que pelo ao menos uma das médias é diferente uma da outra, procedendo se uma análise de comparação de médias pelo teste de Duncan a $5 \%$ de probabilidade. Para as variáveis NFV e NVP que se trata de variáveis quantitativas discretas, adotouse a utilização de teste não paramétrico, pelo fato das mesmas não seguirem distribuição normal. Utilizou-se o aplicativo computacional InfoStat ${ }^{\circledR}$ (Infostat - Software estatístico, Córdoba - Argentina, 2004).

\section{RESULTADOS E DISCUSSÃO}

As características morfogênicas: TALC, TALF, TApF, TSF, Filocrono e DVF obtidas no período chuvoso e período seco, são mostradas na (Tabela 1).

A TALC no período chuvoso foi igual nas alturas de cortes de 30; 40 e $50 \mathrm{~cm}$ e superior em relação às alturas de corte de 10 e $20 \mathrm{~cm}$. No período da seca, o corte na altura de $50 \mathrm{~cm}$ resultou em maior TALC, seguido dos cortes nas alturas de 30 e $40 \mathrm{~cm}$, em média 48,4\% menor e, dos cortes nas alturas de $10 \mathrm{e}$ $20 \mathrm{~cm}$ que tiveram a menor TALC do período (92,4\%). Comparando os períodos, houve diferença $(\mathrm{P}<0,05)$ apenas nas alturas de cortes de 30 e $40 \mathrm{~cm}$, em que o período chuvoso apresentou em média 44 e $67 \%$ a mais de TALC em relação ao período seco do ano. Era de esperar que cortes em alturas mais elevadas resultassem numa maior taxa de alongamento, devido o fato de o resíduo possuir mais folhas, favorecendo a rebrota após o corte.

$\mathrm{O}$ alongamento do colmo incrementa a produção forrageira, porém interfere na estrutura do pasto, comprometendo a eficiência de pastejo em decorrência do 
Rev. Bras. Saúde Prod. Anim., Salvador, v.15, n.2, p.430-439 abr./jun., 2014 http://www.rbspa.ufba.br ISSN 15199940

decréscimo na relação folha/colmo. Portanto, no período das águas, seria necessário maior controle da estrutura do pasto no sentido de favorecer $o$ acúmulo de lâminas foliares em detrimento de colmos, para garantir oferta de forragem de melhor qualidade aos animais em pastejo.

Tabela 1. Características morfogênicas: taxa de alongamento do colmo (TALC), taxa de alongamento da lâmina foliar (TALF), taxa de aparecimento foliar (TApF), filocrono, taxa de senescência foliar (TSF), duração de vida das folhas (DVF) do capim-Xaraés em função de intensidades de cortes $(10,20,30,40$ e $50 \mathrm{~cm})$ ao atingir $95 \%$ de IL durante a rebrotação, no ano de 2011

\begin{tabular}{|c|c|c|c|c|c|c|}
\hline \multicolumn{7}{|c|}{ Alturas de corte } \\
\hline \multicolumn{7}{|c|}{ TALC $(\mathrm{cm} / \mathrm{dia})$} \\
\hline Período & 10 & 20 & 30 & 40 & 50 & $\mathrm{CV}(\%)$ \\
\hline Chuvoso & $0,16^{\mathrm{Ba}}$ & $0,15^{\mathrm{Ba}}$ & $0,66^{\mathrm{Aa}}$ & $0,57^{\mathrm{Aa}}$ & $0,72^{\mathrm{Aa}}$ & 23,63 \\
\hline Seco & $0,05^{\mathrm{Ca}}$ & $0,05^{\mathrm{Ca}}$ & $0,29^{\mathrm{Bb}}$ & $0,38^{\mathrm{Bb}}$ & $0,66^{\mathrm{Aa}}$ & - \\
\hline \multicolumn{7}{|c|}{ TALF (cm/dia) } \\
\hline Chuvoso & $3,18^{\mathrm{Ba}}$ & $3,55^{\mathrm{Ba}}$ & $9,44^{\mathrm{Aa}}$ & $10,34^{\mathrm{Aa}}$ & $11,76^{\mathrm{Aa}}$ & 20,56 \\
\hline Seco & $2,36^{\mathrm{Ba}}$ & $4,05^{\mathrm{ABa}}$ & $3,99^{\mathrm{ABb}}$ & $6,43^{\mathrm{Ab}}$ & $5,51^{\mathrm{Ab}}$ & - \\
\hline \multicolumn{7}{|c|}{ TApF (folha/dia) } \\
\hline Chuvoso & $0,09^{\mathrm{Da}}$ & $0,07^{\mathrm{Da}}$ & $0,19^{\mathrm{Ba}}$ & $0,15^{\mathrm{Ca}}$ & $0,34^{\mathrm{Aa}}$ & 17,51 \\
\hline Seco & $0,07^{\mathrm{Ba}}$ & $0,08^{\mathrm{ABa}}$ & $0,08^{\mathrm{ABb}}$ & $0,11^{\mathrm{ABa}}$ & $0,12^{\mathrm{Ab}}$ & - \\
\hline \multicolumn{7}{|c|}{ Filocrono (dias/folhas) } \\
\hline Chuvoso & $11,63 \mathrm{~A}^{\mathrm{a}}$ & $14,65^{\mathrm{Aa}}$ & $5,36^{\mathrm{BCb}}$ & $6,99^{\mathrm{Ba}}$ & $2,98^{\mathrm{Cb}}$ & 19,48 \\
\hline Seco & $14,25^{\mathrm{Aa}}$ & $12,12^{\mathrm{Aa}}$ & $11,93^{\mathrm{Aa}}$ & $8,81^{\mathrm{BAa}}$ & $8,53^{\mathrm{Aa}}$ & - \\
\hline \multicolumn{7}{|c|}{ TSF (cm/dia) } \\
\hline Chuvoso & $1,02^{\mathrm{Ba}}$ & $0,98^{\mathrm{Ba}}$ & $2,28^{\mathrm{Aa}}$ & $1,43^{\mathrm{Ba}}$ & $2,72^{\mathrm{Aa}}$ & 31,39 \\
\hline Seco & $0,85^{\mathrm{BCa}}$ & $0,13^{\mathrm{Db}}$ & $0,25^{\mathrm{Cb}}$ & $1,73^{\mathrm{Aa}}$ & $1,29^{\mathrm{ABb}}$ & - \\
\hline \multicolumn{7}{|c|}{ DVF (dias/folha) } \\
\hline Chuvoso & $24,56^{\mathrm{BCa}}$ & $19,32^{\mathrm{Ca}}$ & $39,10^{\mathrm{Aa}}$ & $34,33^{\mathrm{Ab}}$ & $25,96^{\mathrm{Bb}}$ & 11,02 \\
\hline Seco & $30,72^{\mathrm{Ca}}$ & $24,11^{\mathrm{Da}}$ & $27,18^{\mathrm{CDb}}$ & $42,90^{\mathrm{Ba}}$ & $49,27^{\mathrm{Aa}}$ & - \\
\hline
\end{tabular}

Medias seguidas da mesma letra, maiúscula nas linhas e minúscula nas colunas, não diferenciam entre si pelo teste de Duncan $(\mathrm{P}>0,05)$

No trabalho de Sousa et al. (2011), com o capim-Xaraés submetido a três alturas de cortes $(15 ; 20$ e $25 \mathrm{~cm})$, foi observado também maior TALC na maior altura de corte. Segundo os autores, nessa altura, a interceptação de luz no início da rebrota foi de $90 \%$ e, mesmo que a competição por luz ainda era baixa, as plantas cortadas a $25 \mathrm{~cm}$ permaneceram em um ambiente mais competitivo do que o aquelas cortadas a 15 e $20 \mathrm{~cm}$, o que pode ter resultado em maior taxa de alongamento do caule. Provavelmente, sob esta condição, os pontos de crescimento das plantas não foram removidos, o que também contribuiu a uma maior taxa de alongamento do caule. Os valores de TALC encontrados na presente pesquisa foram superiores aos obtidos pelos referidos autores, entretanto, vale ressaltar que os mesmos trabalharam com alturas de cortes residuais menores, além das condições edafoclimáticas que diferiram o que explica as variações encontradas.

A TALF diferiu $(\mathrm{P}<0,05)$ no período chuvoso, apenas nos cortes a 10 e $20 \mathrm{~cm}$, nas demais alturas de cortes, a TALF foi 
igual. No período da seca, as alturas de cortes de 40 e $50 \mathrm{~cm}$ tiveram TALF iguais e apresentaram os maiores valores, que foram iguais estatisticamente a TALF obtidas com cortes de 20 e $30 \mathrm{~cm}$ que foi igual à TALF obtida com o corte em 10 $\mathrm{cm}$. Marcelino et al. (2004) observaram efeito da altura de corte e do intervalo entre cortes no alongamento foliar do capim-Marandu, em que a maior altura e o menor intervalo entre cortes acarretaram em maior alongamento foliar. Para o gênero Panicum, Barbosa et al. (2002), verificaram que para o capim-Tanzânia sob lotação rotacionada não houve diferença na TAlF em função da altura do resíduo pós-pastejo.

Na comparação entre as épocas do ano, houve diferença $(\mathrm{P}<0,05)$ entre a TALF nos cortes realizados em 30; 40 e 50 $\mathrm{cm}$, sendo os menores valores obtidos na época da seca. Resultados semelhantes foram obtidos por Mattos et al. (2005), que observaram redução na TALF e elevação na TSF em espécies do gênero Brachiaria sob déficit hídrico. A baixa disponibilidade de água no solo pode ter restringido a absorção de nutrientes, em especial o nitrogênio, cuja principal forma de movimentação do solo para as raízes ocorre através do fluxo de massa (CANTARELLA et al., 2007).

A TApF no período chuvoso foi influenciada $(\mathrm{P}<0,05)$ pelas alturas de cortes e o maior valor encontrado com corte de $50 \mathrm{~cm}$, sendo os valores 55,8 , $44,1,79,4$ e $74 \%$ inferior para os cortes em 40, 30, 20 e $10 \mathrm{~cm}$, respectivamente. No período da seca, a maior TApF, novamente foi obtida com corte a $50 \mathrm{~cm}$ de altura, porém igual estatisticamente aos valores obtidos com cortes em 40; 30 e $20 \mathrm{~cm}$, estes foram iguais a TApF encontrada com cortes em $10 \mathrm{~cm}$. A taxa de aparecimento de folhas é influenciada por fatores do meio. No entanto, diversos trabalhos têm demonstrado que o efeito do corte ou do pastejo sobre essa variável, seria indireto. Barbosa (2004), trabalhando com capim-Tanzânia, não verificou efeito da altura do pasto sobre a TApF, mas observou diferença nessa variável quanto à idade dos perfilhos nos menores intervalos entre pastejos (90 e $95 \%$ de interceptação luminosa), em que perfilho mais novos ( 0 a 2 meses de vida) apresentaram maior TApF relativamente a perfilhos maduros ( 2 a 4 meses) e velhos (acima de 4 meses).

Entre as épocas, houve diferenças $(\mathrm{P}<0,05)$ na $\mathrm{TApF}$ apenas com cortes de 30 e $50 \mathrm{~cm}$ de altura, que apresentaram uma redução de 66,66 e $35,20 \%$, respectivamente, em relação ao período chuvoso. Embora o efeito de limitações hídricas e nutricionais sobre a TApF não apareça de forma clara na literatura, supõe-se que, as melhores condições de crescimento a que as plantas são submetidas nesse período, resultem em um maior fluxo de renovação de tecidos. Então, além de favorecer o acúmulo de forragem, com folhas e o potencial de perfilhamento gerados, a $\mathrm{TApF}$ reduz o tempo necessário para recuperação dos dosséis nessa época do ano.

As alturas de cortes influenciaram $(\mathrm{P}<0,05)$ o filocrono no período chuvoso, sendo que cortes a 10 e $20 \mathrm{~cm}$ apresentaram o maior tempo para o surgimento de duas folhas consecutivas (filocrono), seguido dos cortes a 30; 40 e $50 \mathrm{~cm}$. Este último apresentou o menor filocrono do período chuvoso. No período da seca, não houve diferença $(\mathrm{P}>0,05)$ do filocrono em função das alturas de cortes.

Entre as épocas do ano não houve efeito $(\mathrm{P}>0,05)$ das alturas de cortes sobre $\mathrm{O}$ filocrono. O filocrono, ou seja, o intervalo de tempo para o aparecimento de duas folhas consecutivas seguiu padrão de resposta oposto àquele 
observado para o aparecimento foliar, estando os maiores valores relacionados ao período seco, o que era esperado, uma vez que o filocrono foi calculado como sendo o inverso da TApF. Barbosa (2004) observou mudanças no filocrono durante as diferentes estações do ano, sendo que os maiores valores de filocrono ocorreram durante o inverno e os menores, no verão. Corroborando com os resultados obtidos no presente trabalho.

A TSF no período chuvoso foi influenciada $(\mathrm{P}<0,05)$ pelas alturas de cortes em que 30 e $50 \mathrm{~cm}$ apresentaram a maior TSF, nas demais alturas de cortes os valores foram iguais. No período da seca, cortes a $40 \mathrm{~cm}$ resultaram em maior TSF que, foi igual às TSF das alturas de cortes de $50 \mathrm{e}$ $10 \mathrm{~cm}$, respectivamente, seguido de $30 \mathrm{e}$ $20 \mathrm{~cm}$. O corte em $20 \mathrm{~cm}$ resultou em menor TSF, no período.

Entre as épocas, houve diferenças $(\mathrm{P}<0,05)$, em que as alturas de 10 e 40 $\mathrm{cm}$ foram iguais apresentando a maior TSF, no período da seca. Nas demais alturas de cortes a TSF foi similar.

Normalmente, maiores alturas de resíduos proporcionam maior participação de material morto por apresentarem maior índice de área foliar, o que pode aumentar a competição por luz, desencadeando o processo de senescência das folhas baixeiras do perfilho. Sbrissia (2008) observou em pastos de B. brizantha cv. Marandu sob lotação contínua, um acréscimo na senescência de folhas com o decréscimo da intensidade de pastejo. Entretanto, nesse trabalho, menores alturas de cortes 10 e $20 \mathrm{~cm}$, proporcionaram valor de senescência semelhante aos tratamentos de 30; 40 e $50 \mathrm{~cm}$, provavelmente o maior intervalo de recuperação de dossel necessário nesse tratamento, fez com que a TSF aumentasse. Uma vez que, depois de atingido o período de duração de vida das folhas, a senescência começa a surgir nas primeiras folhas produzidas.

A TSF é obtida dividindo o valor de senescência encontrado por folha (em $\mathrm{cm}$ ), pela quantidade de dias decorridos no período avaliação. Como no período seco foi obtido apenas um corte, sendo necessários 154 dias para recuperação do capim, o valor de TSF foi menor, quando comparado ao do período chuvoso do ano.

No período chuvoso, a DVF foi afetada $(\mathrm{P}<0,05)$ pelas alturas de cortes, onde cortes a 30 e $40 \mathrm{~cm}$ foram iguais e tiveram maior DVF, seguido dos cortes a 50 e $10 \mathrm{~cm}$. Cortes realizados a $20 \mathrm{~cm}$ de altura resultaram em menor DVF. No período da seca, cortes realizados a 50 $\mathrm{cm}$ resultaram em maior DVF e, novamente cortes a $20 \mathrm{~cm}$ resultou em menor DVF.

A comparação das épocas revelou efeito significativo $(\mathrm{P}<0,05)$ em que, cortes a $30 \mathrm{~cm}$ resultaram em menor DVF no período da seca, já no período chuvoso cortes a $40 \mathrm{~cm}$ resultou em menor DVF. A DVF representa o período durante o qual há acúmulo de folhas no perfilho, sem que seja detectada perda por senescência (LEMAIRE, 1997). Então, no período chuvoso, as condições de crescimento são favorecidas, cortes mais baixos $(10$ e $20 \mathrm{~cm})$ e muito elevado $(50 \mathrm{~cm})$ no capim-Xaraés promovem redução na DVF.

Houve diferença $(\mathrm{P}<0,05)$ no período chuvoso da altura de corte sobre o NFV. Cortes a 20 e $40 \mathrm{~cm}$ apresentam maior NFV que é igual às alturas de cortes de 30 e 50 que, por sua vez é igual a $10 \mathrm{~cm}$. No período da seca, o NFV não variou $(\mathrm{P}>0,05)$ em função das alturas de cortes (Tabela 2).

Entre as épocas, o maior NFV foi no período chuvoso, entretanto as alturas de cortes de 20 e $30 \mathrm{~cm}$ foram iguais nos dois períodos. Isso porque, embora o NFV seja determinado geneticamente, 
está sujeito a mudanças em função das condições de meio e de manejo da pastagem como disponibilidade hídrica, severidade de desfolhação, dentre outros.

A capacidade das gramíneas forrageiras em acumular folhas vivas e atingir o IAF "critico" é influenciada pelo tempo em que a folha permanece verde. Segundo Gomide et al. (2006), o NFV, a equivalência entre a TALF e senescência foliar por perfilho, bem como a redução do alongamento do colmo, são critérios que se apresentam como orientadores do manejo de gramíneas tropicais cespitosas.

Tabela 2. Características estruturais: número de folhas vivas por perfilho (NFV), número vivo de perfilhos (NVP) e comprimento final da lâmina foliar (CF) do capim-Xaraés em função de intensidades de cortes $(10,20,30,40$ e $50 \mathrm{~cm})$ ao atingir 95\% de IL durante a rebrotação, no ano de 2011

\begin{tabular}{lcccccc}
\hline \multicolumn{7}{c}{ Alturas de corte } \\
\hline Período & 10 & 20 & \multicolumn{7}{c}{30} & 40 & 50 & $\mathrm{CV}(\%)$ \\
\hline \multicolumn{7}{c}{ NFV(folhas/perfilho) $)^{*}$} \\
\hline Chuvoso & $4,25^{\mathrm{Ba}}$ & $4,33^{\mathrm{Aba}}$ & $7^{\mathrm{ABa}}$ & $9,75^{\mathrm{Aa}}$ & $9,25^{\mathrm{ABa}}$ & $*$ \\
Seco & $2^{\mathrm{Ab}}$ & $1,5^{\mathrm{Ab}}$ & $3,5^{\mathrm{Aa}}$ & $3^{\mathrm{Ab}}$ & $2,25^{\mathrm{Ab}}$ & - \\
\hline \multicolumn{7}{c}{$\mathrm{NVP}($ perfilhos$/$ planta) } \\
\hline Chuvoso & $9,5^{\mathrm{Aa}}$ & $10^{\mathrm{Aa}}$ & $8,83^{\mathrm{Aa}}$ & $7,75^{\mathrm{Aa}}$ & $6,88^{\mathrm{Aa}}$ & $*$ \\
Seco & $4^{\mathrm{Ab}}$ & $7^{\mathrm{Aa}}$ & $6,5^{\mathrm{Aa}}$ & $6^{\mathrm{Aa}}$ & $3,5^{\mathrm{Aa}}$ & - \\
\hline \multicolumn{7}{c}{$\mathrm{CF}(\mathrm{cm})^{* *}$} \\
\hline Chuvoso & $26,07^{\mathrm{Ba}}$ & $25,82^{\mathrm{Ba}}$ & $61,39^{\mathrm{Aa}}$ & $57,66^{\mathrm{Aa}}$ & $63,13^{\mathrm{Aa}}$ & 14,09 \\
Seco & $23,62^{\mathrm{Ba}}$ & $30,33^{\mathrm{Ba}}$ & $33,19^{\mathrm{Bb}}$ & $62,52^{\mathrm{Aa}}$ & $53,33^{\mathrm{Aa}}$ & - \\
\hline
\end{tabular}

Médias seguidas da mesma letra, maiúscula nas linhas e minúscula nas colunas, não diferenciam entre si pelo teste $t$ de Student $(\mathrm{p}<0,05)$.

*NFV e NVP foram submetidas a analise não paramétrica, pelo teste de KruskalWallis.

**Análise de variância para variáveis com distribuição normal.

O número de perfilhos vivos na touceira não foi influenciado $(\mathrm{P}>0,05)$ pelas alturas de cortes e nem pelas épocas do ano. Para Da Silva \& Pedreira (1997), sob desfolhação frequente e intensa, as plantas podem apresentar perfilhamento abundante, habito de crescimento prostrado e elevado ritmo de expansão foliar, $o$ que possibilita maior interceptação de luz após o corte. Entretanto, a desfolhação muito severa pode esgotar as reservas de energia da planta, isso aliada à redução de água disponível para as plantas no período, pode ter comprometido a densidade de perfilhos.
$\mathrm{O}$ CF diferiu $(\mathrm{P}<0,05)$ entre as alturas de cortes. Cortes a 30; 40 e $50 \mathrm{~cm}$ apresentaram $\mathrm{CF}$ maiores e iguais entre si em relação as alturas de cortes de 10 e $20 \mathrm{~cm}$, no período chuvoso. No período seco, cortes a 40 e $50 \mathrm{~cm}$, resultaram em maior $\mathrm{CF}$, comparado ao $\mathrm{CF}$ das demais alturas. Entre os períodos do ano, só houve diferença $(\mathrm{P}<0,05)$ na altura de $30 \mathrm{~cm}$ em que $\mathrm{o}$ período seco apresentou maior $\mathrm{CF}$, nos demais tratamentos o $\mathrm{CF}$ foi igual.

$\mathrm{O}$ menor $\mathrm{CF}$ obtido no período seco poderia favorecer as plantas em períodos de baixa precipitação, uma vez que, um menor comprimento de folha possibilitaria, ao dossel, um perfil mais 
Rev. Bras. Saúde Prod. Anim., Salvador, v.15, n.2, p.430-439 abr./jun., 2014 http://www.rbspa.ufba.br ISSN 15199940

ereto, o que acarretaria uma maior exposição da área foliar à radiação direta, reduzindo a transpiração da planta, além de permitir uma distribuição mais eficiente da luz no interior do dossel (SOUZA JUNIOR, 2007).

Cortes mais leniente entre 30 e $50 \mathrm{~cm}$, no capim-Xaraés resultam em maior TALC, TALF, TApF, TSF, DVF, NFV e CF. Portanto, a altura de corte do capim-Xaraés recomendada para essas condições edafoclimáticas situa-se nessa faixa.

As características TALC, TALF, TApF, TSF, NFV e CFF apresenta valores mais elevados durante $\mathrm{o}$ período chuvoso. Enquanto, o filocrono e, a DVF em $40 \mathrm{~cm}$ apresenta valores mais elevados no período da seca.

O NVP não é afetado pelas alturas de cortes ou época do ano.

\section{AGRADECIMENTOS}

À Fundação de Amparo à Pesquisa e ao Desenvolvimento Científico e Tecnológico do Maranhão (FAPEMA), pelo financiamento do Projeto e bolsa de iniciação científica. Ao Conselho Nacional de Pesquisa (CNPQ) pela concessão de bolsas de iniciação científica e ao grupo de estudo e pesquisa FOPAMA pela ajuda na condução do experimento.

\section{REFERÊNCIAS}

\section{ALEXANDRINO, E.; NASCIMENTO}

JÚNIOR, D.; REGAZZI, A.J.;

MOSQUIM, P.R.; ROCHA, F.C.;

SOUZA, D. de P. Características

morfogênicas e estruturais na rebrotação

da Brachiaria brizantha cv. Marandu

submetida a três doses de nitrogênio.

Revista Brasileira de Zootecnia, v.33, n.6, p.1372-1379, 2004.
BARBOSA, R.A. Características

morfofisiológicas e acúmulo de

forragem em capim-Tanzânia

(Panicum maximum Jacq. cv.

Tanzânia) submetido a freqüências e intensidades de pastejo. 2004. 122p.

Tese (Doutorado em Zootecnia) -

Universidade Federal de Viçosa,

Viçosa.

BARBOSA, R.A.; NASCIMENTO

JÚNIOR, D. do; EUCLIDES, V.P.B.; REGAZZI, A.J.; FONSECA, D.M. da. Características morfogênicas e acúmulo de forragem do capim-tanzânia (Panicum maximum Jacq. cv. Tanzânia) em dois resíduos forrageiros póspastejo. Revista Brasileira de Zootecnia, v.31, n.2, p.583-593, 2002.

CANTARELLA, H. Nitrogênio. In: NOVAIS, R.F.; ALVAREZ, V.H.; BARROS, N.F. FONTES, R.L.F; CANTARUTTI, R.B.; NEVES, J.C.L. (Eds.). Fertilidade do solo. Viçosa: SBCS, 2007. p.375-470.

DA SILVA, S.C.; PEDREIRA, C.G.S. Princícios de ecologia aplicados ao manejo de pastagem. In: SIMPÓSIO SOBRE ECOSSISTEMAS DE PASTAGENS, 3., 1997, Jaboticabal,. Anais... Jaboticabal: FUNESP, 1997. p.1-62.

DIAS FILHO, M.B. Growth and biomass allocation of the $\mathrm{C}_{4}$ grasses Brachiaria brizantha and Brachiaria humidicola inder shade. Pesquisa Agropecuária Brasileira, v.3, n.12, p.2335-2341, 2000.

EMPRESA BRASILEIRA DE PESQUISA AGROPECUÁRIA EMBRAPA. Sistema brasileiro de classificação de solos. Brasília, 1999. $412 \mathrm{p}$. 
Rev. Bras. Saúde Prod. Anim., Salvador, v.15, n.2, p.430-439 abr./jun., 2014 http://www.rbspa.ufba.br ISSN 15199940

GOMIDE, C.A.M.; GOMIDE, J.A.; PACIULLO, D.S.C. Morfogênese como ferramenta para o manejo de pastagens. Revista Brasileira de Zootecnia, v.35, p.554-579, 2006.

GOMIDE, C.A.M.; GOMIDE, J.A.; HUAMAN, C.A.M.; PACIULLO, D.S.C. Fotossíntese, reservas orgânicas e rebrota do capim-mombaça (Panicum maximum Jacq.) sob diferentes intensidades de desfolhação do perfilho principal. Revista Brasileira de Zootecnia, v.31, n.6, p.2165-2175, 2002.

\section{INFOSTAT. INFOSTAT. Versión}

2004. Córdoba, Argentina: Universidad Naciona de Córdoba, 2004.

LEMAIRE, G. The physiology of grass growth under grazing: tissue turnover. In: SIMPÓSIO INTERNACIONAL SOBRE PRODUÇÃO ANIMAL EM PASTEJO, 1997, Viçosa, MG. Anais... Viçosa, MG: Universidade Federal de Viçosa, 1997. p.115-144.

MATTOS, J.L.S.; GOMIDE, J.A.; HUAMAN, C.A.M. Crescimento de espécies do gênero Brachiaria, sob déficit hídrico, em casa de vegetação.

Revista Brasileira de Zootecnia, v.34, n.3, p.746-754, 2005.

MARCELINO, K.R.A.; NASCIMENTO JÚNIOR, D.; DA SILVA, S.C.; DIFANTE, G.S.; BARBOSA, R.A.; EUCLIDES, V.B.P.; FONSECA, D.M.; SILVEIRA, M.C. T. da; MATTOS, J.L.S.; GOMIDE, J.A.; HUAMAN, C.A.M. Crescimento de espécies do gênero Brachiaria, sob déficit hídrico, em casa de vegetação. Revista Brasileira de Zootecnia, v.34, n.3, p.746-754, 2005.
NABINGER, C.; PONTES, L. da S. Morfogênese de plantas forrageiras e estrutura do pasto. In: MATTOS, W.R.S. (Ed.). A produção animal na visão dos brasileiros. Piracicaba: Sociedade Brasileira de Zootecnia, 2001. 18p.

PACIULLO, D.S.C., DERESZ, F.; AROEIRA, L.J.M.; MORENZ, M.J.F.; VERNEQUE, R. da S. Morfogênese e acúmulo de biomassa foliar em pastagem de capim-elefante avaliada em diferentes épocas do ano. Pesquisa Agropecuária Brasileira, v.38, n.7, p.881-887, 2003.

SBRISSIA, A.F.; DA SILVA, S.C. Compensação tamanho/densidade populacional de perfilhos em pastos de capim-marandu. Revista Brasileira de Zootecnia, v.37, n.1, p.35-47, 2008.

SOUSA, B.M.L.; NASCIMENTO JUNIOR, D.; RODRIGUES, C.S.; MONTEIRO, H.C. de F.; SILVA, S.C. da; FONSECA, D.M. da; SBRISSIA, A.F. Características morfogênicas e estruturais do capim-xaraés submetidos a alturas de corte. Revista Brasileira de Zootecnia, v.40, n.1, p.53-59, 2011.

SOUZA JUNIOR, S.J. Estrutura do dossel, interceptação de luz e acúmulo de forragem em pastos de capimmarandu submetidos a estratégias de pastejo rotativo por bovinos de corte. 2007. 122p. Dissertação (Mestrado em Ciência Animal e Pastagens) Universidade de São Paulo, Piracicaba.

Data de recebimento: 20/01/2014

Data de aprovação: 19/06/2014 